\title{
Survey of neuromuscular monitoring and assessment of postoperative residual neuromuscular block in a postoperative anaesthetic care unit
}

\author{
Xu Feng $\underline{\mathrm{Lin}}^{1}$, MD, MMed, Christine Yoke Kuen Yong${ }^{1}$, MBBS, May Un Sam Mok ${ }^{1}$, MBChB, FRCA,
} Poopalalingam Ruban ${ }^{1}$, MBBS, MMed, Patrick Wong $^{1}$, MBBS, FRCA

\begin{abstract}
INTRODUCTION The use of neuromuscular blocking agents (NMBAs) is common during general anaesthesia. Neuromuscular monitoring with a peripheral nerve stimulator (PNS) is essential to prevent postoperative residual neuromuscular block (PRNB), defined as a train-of-four (TOF) ratio < 0.9. PRNB remains a common complication and may contribute to morbidity in the postoperative anaesthetic care unit (PACU).

METHODS An online survey was sent to anaesthesiologists in our department to assess their knowledge and clinical practices related to neuromuscular blockade. Next, a study was conducted on adult patients scheduled for elective surgery under general anaesthesia requiring NMBAs. Upon admission to the PACU, TOF monitoring was performed.

RESULTS A large proportion of anaesthesiologists showed a lack of knowledge of neuromuscular blockade or nonadherence to the best clinical practices associated with it. The majority (98.7\%) stated that they did not routinely use PNS monitoring. In the clinical study, TOF monitoring was only used in $17.9 \%$ of the 335 patients who were assessed. The prevalence of PRNB was $33.4 \%$ and was associated with the elderly (age $\geq 65$ years), a higher dose of NMBA used, a shorter duration of surgery, and a shorter duration between the last dose of NMBA and measurement of PRNB in the PACU. The incidence of adverse symptoms in the PACU was observed to be higher in patients with PRNB.

CONCLUSION PRNB remains a clinically significant problem, but routine PNS monitoring is rare in our institution. This is compounded by inadequate knowledge and poor adherence to best clinical guidelines related to neuromuscular blockade.
\end{abstract}

Keywords: monitoring, neuromuscular block, peripheral nerve stimulator, postoperative anaesthetic care unit

\section{INTRODUCTION}

The use of neuromuscular blocking agents (NMBAs) during anaesthesia is common. Neuromuscular monitoring with a peripheral nerve stimulator (PNS) is essential to prevent postoperative residual neuromuscular block (PRNB). ${ }^{(1)}$ PRNB remains a common but usually undetected complication during the postoperative period. It occurs in $40 \%-60 \%$ of patients receiving intraoperative $\mathrm{NMBAs}^{(2-4)}$ and is associated with increased morbidity, including pulmonary aspiration, ${ }^{(5)}$ airway obstruction, ${ }^{(6)}$ hypoxia ${ }^{(7,8)}$ and even mortality. ${ }^{(9)}$

PRNB can be assessed with clinical tests (no longer recommended) and neuromuscular monitoring using a PNS. ${ }^{(1,10)}$ The latter can be used to monitor the degree of and recovery from neuromuscular block. It is also used to guide the timing and dosage of reversal agent administration. There are various modes of monitoring, including the train-of-four (TOF) mode, which delivers four supramaximal electrical stimuli (T1, T2, T3 and T4) at $2 \mathrm{~Hz}$, with an interval of at least 10 seconds between each TOF. ${ }^{(11)}$ Qualitative TOF is determined by the number of twitches detected and/or the degree of fade (decreasing amplitude of successive twitches indicating PRNB) observed via visual or tactile means. However, these are not reliable compared with quantitative monitoring. ${ }^{(12-14)}$ Quantitative TOF is the TOF ratio, or the ratio of the fourth (T4) to the first (T1) twitches, and is most commonly measured using an acceleromyography device. Recovery from paralysis after NMBA administration, defined as a TOF ratio at the adductor pollicis $\geq 0.9$, can only be determined accurately with quantitative monitoring. ${ }^{(15)}$ PRNB therefore occurs when the TOF ratio is $<0.9$, which is associated with impaired pharyngeal function, increased risk of aspiration, weakness of upper airway muscles and airway obstruction. ${ }^{(16)}$ PNS for assessing neuromuscular blockade is recommended for neuromuscular monitoring following NMBA administration during all stages of anaesthesia, and is best performed using a quantitative monitor. ${ }^{(1,17)}$

However, many anaesthesiologists fail to use or incorrectly use the TOF monitor, leading to an increased incidence of PRNB. ${ }^{(18,19)}$ In Singapore, there is no data on the incidence of PRNB. Therefore, we initially conducted a survey among anaesthesiologists, and junior trainees on rotation, in our department to assess their knowledge of and clinical practices pertaining to PRNB. We subsequently performed a prospective observational study to establish the prevalence of and factors associated with PRNB in the postoperative anaesthetic care unit (PACU).

\section{METHODS}

For the anonymous online survey, we sought ethical approval from the SingHealth Centralised Institutional Review Board (CIRB reference 2016/3076), but it was exempted from CIRB approval. All specialist anaesthesiologists and trainees on rotation in our 
department were invited to voluntarily participate in the survey. The survey comprised 25 multiple-choice questions (Appendix 1). The initial questions examined (a) the demographics of the anaesthesiologists, while the others were related to PRNB, NMBA, reversal agents and neuromuscular monitoring: (b) training; (c) personal clinical preferences; and (d) assessing their knowledge of (Questions 13, 14, 16, 17, 19-23 and 25) and adherence to clinical best practices (Questions 2, 3, 6-8, 18 and 24) related to preventing PRNB.

The study protocol was approved by the hospital ethics committee (SingHealth CIRB reference 2016/2478) and was registered with ClinicalTrials.gov (ID NCT02930629). Adult patients (aged $\geq 21$ years) who were scheduled for elective operation in the main operating theatre under general anaesthesia and who required tracheal intubation using NMBAs were screened and recruited in the pre-anaesthetic assessment clinic at Singapore General Hospital, Singapore. Surgical specialties in the main operating theatre did not include cardiology and urology. Day surgery theatres were excluded. Patients were excluded if it was not possible to apply TOF monitoring on the ulnar nerve area of their forearms or they had underlying neuromuscular disease. Written informed consent was obtained from all participants.

Patient characteristics such as age, gender, body mass index and American Society of Anesthesiologists (ASA) physical status score were recorded. Relevant perioperative data was recorded: timing, dosage and type of NMBA administered; duration of surgery and general anaesthesia; anaesthetic agent used for maintenance; and type and dose of reversal agents used.

Intraoperatively, the use of NMBAs and reversal agents was at the attending anaesthesiologist's discretion. Immediately after the patients' arrival at the PACU, PRNB was assessed with the use of a quantitative PNS (TOF-Watch ${ }^{\circledR}$ SX, Organon Inc, Ireland). Two electrocardiography electrodes were placed $4 \mathrm{~cm}$ apart over the ulnar nerve at the distal part of the patient's wrist. A 50-mA TOF stimulus was applied, and the motor response of the thumb (adductor pollicis muscle) was measured to assess the degree of PRNB via the TOF count; when the TOF count was 4, the TOF ratio was measured. A second set of TOF results was then obtained. The final TOF ratio was the average of the two sets of TOF stimulations. If the discrepancy between the two initial readings was $>10 \%$, two more TOF stimulations were applied, ${ }^{(18)}$ and the average of the two closest measurements was calculated. Each set of TOF stimulations was taken 15 seconds apart. The presence of PRNB was also assessed by clinical tests (five-second hand grip test and five-second head lift test). The PACU nurses were asked to monitor the patients for any adverse incidents associated with PRNB (airway obstruction, desaturation and complaints of muscle weakness or blurred/double vision).

The primary outcome measure of our clinical study was the prevalence of PRNB on arrival in the PACU. The secondary outcome was the prevalence of PRNB-associated adverse symptoms in the PACU. Study variables that were recorded included: duration of surgery; administration and dosages of NMBAs and reversal agents; prevalence of intraoperative TOF monitoring; and temperature on arrival at the PACU.
For the survey, we examined the incidence of correct and incorrect answers to the knowledge- and best practice-based questions (Appendix 2). Incorrect answers were defined as those that were the wrong option or 'Don't know'. For the clinical study, based on an estimated prevalence of PRNB of $40 \%$, a sample size of 305 participants would provide a precision level of 5.5\%. ${ }^{(20)}$ Results were expressed as numerical values and percentages for categorical variables, mean \pm standard deviation for normally distributed continuous data, and median with interquartile range (Q1-Q3) for skewed continuous data. The total dose of NMBA administered was expressed as $95 \%$ effective dose mg per hour per $\mathrm{kg}$ (i.e. $\mathrm{ED}_{95} \mathrm{mg} / \mathrm{kg} / \mathrm{h}$ ). ${ }^{(21)}$ The $\mathrm{ED}_{95}$ for atracurium and rocuronium is $0.2 \mathrm{mg} / \mathrm{kg}$ and $0.3 \mathrm{mg} / \mathrm{kg}$, respectively. ${ }^{(22,23)}$ Univariate analysis was performed. For categorical data, $\chi^{2}$ test or Fisher's exact test were used. For continuous data, Student's $t$-test was used. We further assessed the relationship between PRNB and potential risk factors using a logistic regression model including variables of clinical importance and those with $p<0.1$ in the univariate analysis. Sensitivity, specificity and predictive values of the clinical qualitative tests were calculated according to standard formulae. All tests were two-tailed and a p-value $<0.05$ was considered significant. Statistical analysis was performed with PASW Statistics version 18.0 (SPSS Inc, Chicago, IL, USA).

\section{RESULTS}

For the survey, we received a total of 150 out of 202 responses, a $74.3 \%$ response rate. The survey results can be found in Appendix 2. Incorrect answers ranged from $0 \%$ to $68.7 \%$. $68.7 \%$ of the participants gave an incorrect answer when asked for the definition of NMBA duration of action, $45.3 \%$ did not know when the ideal time for neostigmine administration was, and $45.3 \%$ did not know the definition of when a patient is fully reversed. Non-adherence to best clinical practices was also variable (range 0\%-98.7\%). 98.7\% did not routinely use PNS following NMBA administration, and $94.7 \%$ did not use TOF count during laparoscopic surgery and to guide reversal administration.

For the clinical study, 400 patients were enrolled after screening at the preoperative anaesthetic clinic in Singapore General Hospital, Singapore, from September 2016 to July 2017. Data was available for 335 patients (Table I), as 15 patients were excluded due to technical issues with the PNS, nine patients were sent to the intensive care unit postoperatively, eight patients were not given NMBAs, 16 patients had their operations cancelled; six patients withdrew from the study after enrolment, and 11 patients were missed as the research team was not informed of their arrival at the PACU. The prevalence of PRNB in patients arriving at the PACU was $33.4 \%(n=112)$. Adverse symptoms and incidents noted in the PACU were desaturation $(2.7 \%, \mathrm{n}=9)$, dysphagia $(0.6 \%, \mathrm{n}=2)$, dyspnoea $(2.1 \%, \mathrm{n}=7)$, weakness $(0.9 \%, \mathrm{n}=3)$ and blurred/double vision $(3.0 \%, \mathrm{n}=10)$. Patients with PRNB had a higher chance of having these symptoms, and this was statistically significant (Table II). No patient required emergency reintubation in the PACU, but one patient with a TOF count of 3 developed stridor that rapidly resolved after a further dose of neostigmine (following the initial dose in the theatre). 
Table I. Demographic data and clinical characteristics of the patients $(n=335)$.

\begin{tabular}{|c|c|}
\hline Parameter & No. (\%) \\
\hline Age* $^{*}(y r)$ & $54(42-64)$ \\
\hline \multicolumn{2}{|l|}{ Gender } \\
\hline Male & $145(43.3)$ \\
\hline Female & $190(56.7)$ \\
\hline \multicolumn{2}{|l|}{ ASA status } \\
\hline 1 & $58(17.3)$ \\
\hline II & $205(61.2)$ \\
\hline III & $71(21.2)$ \\
\hline Height $^{\dagger}(\mathrm{cm})$ & $161.4 \pm 10.1$ \\
\hline Weight $^{\dagger}$ (kg) & $69.8 \pm 19.5$ \\
\hline Body mass index ${ }^{\dagger}\left(\mathrm{kg} / \mathrm{m}^{2}\right)$ & $26.7 \pm 6.3$ \\
\hline Duration of operation* (min) & $176(84-226)$ \\
\hline \multicolumn{2}{|l|}{ Type of operation } \\
\hline Abdominal surgery & $166(49.6)$ \\
\hline Non-abdominal surgery & $169(50.4)$ \\
\hline \multicolumn{2}{|l|}{ Anaesthesia maintenance } \\
\hline Inhalational agent & $316(94.3)$ \\
\hline Propofol TIVA & $19(5.7)$ \\
\hline \multicolumn{2}{|l|}{ NMBA used } \\
\hline Atracurium & $285(85.1)$ \\
\hline Rocuronium & $50(14.9)$ \\
\hline NMBA dose* $\left(E_{95} / \mathrm{h}\right)$ & $1.86(1.03-2.35)$ \\
\hline \multicolumn{2}{|l|}{ Intraoperative NM monitoring } \\
\hline Qualitative TOF & $49(14.6)$ \\
\hline Quantitative TOF (TOF-Watch) & $11(3.3)$ \\
\hline No TOF monitoring & $275(82.1)$ \\
\hline \multicolumn{2}{|l|}{ Reversal agent given } \\
\hline Neostigmine & $275(82.1)$ \\
\hline Sugammadex & $12(3.5)$ \\
\hline No reversal & $48(14.3)$ \\
\hline Temperature in $\mathrm{PACU}^{\dagger}\left({ }^{\circ} \mathrm{C}\right)$ & $35.9 \pm 0.8$ \\
\hline
\end{tabular}

*Data presented as median (interquartile range). + Data presented as mean \pm standard deviation. ASA: American Society of Anesthesiologists; ED: effective dose; NM: neuromuscular; NMBA: neuromuscular blocking agent; PACU: postoperative anaesthetic care unit; TIVA: total intravenous anaesthesia (propofol infusion); TOF: train-of-four

Univariate analysis showed no statistically significant differences in the prevalence of PRNB according to body mass index $\left(<30 \mathrm{~kg} / \mathrm{m}^{2} \mathrm{vs} . \geq 30 \mathrm{~kg} / \mathrm{m}^{2}\right)$, ASA class, type of surgery, presence of hypothermia, type of anaesthetic/NMBA given or reversal agent given (Table III). A greater proportion of patients who did not receive TOF monitoring had PRNB compared to those who received it, although the difference was not statistically significant.

The prevalence of PRNB was associated with being elderly ( $\geq 65$ years), a higher dose of NMBA used, shorter duration of surgery (149.8 minutes vs. 189.5 minutes) and a shorter duration between last dose of NMBA and TOF measurement in PACU (89.9 minutes vs. 133.8 minutes). Multivariate logistic regression showed that elderly status and a shorter duration between the last dose of NMBA and TOF measurement in the PACU were independent
Table II. Adverse symptoms and incidents in the postoperative anaesthetic care unit.

\begin{tabular}{|llll|}
\hline \multirow{2}{*}{ Parameter } & \multicolumn{2}{c}{ No. (\%) } & p-value \\
\cline { 2 - 3 } & $\begin{array}{l}\text { No PRNB } \\
(\mathbf{n}=\mathbf{2 2 3})\end{array}$ & $\begin{array}{l}\text { PRNB } \\
(\mathbf{n}=\mathbf{1 1 2})\end{array}$ & \\
\hline Desaturation* & $5(2.2)$ & $4(3.6)$ & 0.489 \\
\hline Dysphagia & $0(0)$ & $2(1.8)$ & 0.111 \\
\hline Dyspnoea & $1(0.4)$ & $6(5.4)$ & 0.006 \\
\hline Weakness & $0(0)$ & $3(2.7)$ & 0.037 \\
\hline Blurred/double vision & $3(1.3)$ & $7(6.3)$ & 0.018 \\
\hline
\end{tabular}

*Defined as drop in $\mathrm{SpO}_{2}<95 \%$ on room air. PRNB: postoperative residual neuromuscular block

factors associated with PRNB (Table IV). The five-second hand grip test had a sensitivity of $24 \%$, specificity of $72 \%$, positive predictive value (PPV) of $52 \%$ and negative predictive value (NPV) of $81 \%$. The five-second head lift test showed a sensitivity of $41 \%$, specificity of $80 \%$, PPV of $48 \%$ and NPV of $77 \%$.

During the TOF measurements, $85.4 \%$ of patients were easily roused and responsive to commands, falling into either the mildly or moderately sedated categories. Despite that, most patients tolerated the stimulation current of $50 \mathrm{~mA}$ well. Among the 335 patients, $15(4.5 \%)$ reported no pain, $240(71.6 \%)$ reported mild pain, and $77(23.0 \%)$ reported moderate pain. Only $3(0.9 \%)$ patients complained of severe pain during the TOF stimulations.

\section{DISCUSSION}

Our survey demonstrated that the rate of incorrect responses was high and that there was poor adherence to best clinical practices among anaesthesiologists. In the clinical study, the prevalence of PRNB in patients on their arrival at the PACU was 33.4\%, and these patients had a significantly higher chance of having adverse symptoms. This is slightly less than in other reports, ${ }^{(2-4)}$ which may be due to various factors: differences in definitions of PRNB (e.g. the diagnosing criteria for TOF ratio have changed since the 1970s), patient heterogeneity and the type of anaesthetic agents used. We herein discuss the results in relation to monitoring, reversal agents, duration of NMBA and risk factors for PRNB.

The use of PNS monitoring is recommended following administration of NMBA. ${ }^{(1)}$ However, from our survey, only $32.0 \%$ of the respondents agreed and $6.0 \%$ strongly agreed with this recommendation. In a subsequent question, only $2.7 \%$ and $1.3 \%$ of our respondents stated that they used PNS monitoring in $>50 \%$ or in $100 \%$ of cases, respectively. This is comparable with results from a national survey of anaesthesiologists in Singapore by Teoh et al, in which only $13.1 \%$ of respondents said they monitored routinely. ${ }^{(24)}$ In the clinical study, only $17.9 \%$ of our patients received any TOF monitoring intraoperatively, and only $3.3 \%$ had quantitative TOF monitoring.

The reason for the low rate of PNS monitoring use is multifactorial, including perception of the prevalence and consequences of PRNB use, PNS training, and availability of and confidence in using PNS monitoring. 34.0\% of our respondents did not use PNS monitoring as they 'don't think it's necessary'. This may be due to the perceived low incidence of PRNB. 24\% of our respondents underestimated its 
Table III. Risk factors associated with postoperative residual neuromuscular block (PRNB), assessed using univariate analysis.

\begin{tabular}{|c|c|c|c|}
\hline \multirow[t]{2}{*}{ Risk factor } & \multicolumn{2}{|c|}{ No. (\%) } & \multirow[t]{2}{*}{ p-value } \\
\hline & No PRNB $(n=223)$ & PRNB $(n=112)$ & \\
\hline Elderly ( $\geq 65$ yr) & $65(29.1)$ & $46(41.1)$ & 0.014 \\
\hline ASA status $\geq 3$ & $50(22.4)$ & $22(19.6)$ & 0.559 \\
\hline Obesity (BMI $\geq 30$ kg/m²) & $55(24.7)$ & $27(24.1)$ & 0.911 \\
\hline Abdominal surgery & $106(47.5)$ & $60(53.6)$ & 0.297 \\
\hline Hypothermia $\left(<36^{\circ} \mathrm{C}\right)$ & $113(50.7)$ & $54(48.2)$ & 0.671 \\
\hline Atracurium (vs. rocuronium) & $186(83.4)$ & $99(88.4)$ & 0.227 \\
\hline Inhalational maintenance (vs. TIVA) & $209(93.7)$ & $108(96.4)$ & 0.442 \\
\hline No reversal & $36(16.1)$ & $12(10.7)$ & 0.181 \\
\hline No TOF monitoring & $178(79.8)$ & $97(86.6)$ & 0.125 \\
\hline Operation duration (min) & 189.5 & 149.8 & 0.003 \\
\hline NMBA total dose $\left(\mathrm{ED}_{95} / \mathrm{h}\right)$ & 1.71 & 2.16 & 0.002 \\
\hline Time from last NMBA to TOF in PACU (min) & 133.8 & 89.9 & $<0.001$ \\
\hline
\end{tabular}

ASA: American Society of Anesthesiologists; BMI: body mass index; ED: effective dose; NMBA: neuromuscular blocking agent; PACU: postoperative anaesthetic care unit; TIVA: total intravenous anaesthesia (propofol infusion); TOF: train-of-four

Table IV. Determinants of postoperative residual neuromuscular block assessed using multivariate logistic regression.

\begin{tabular}{|llll|}
\hline Parameter & OR & $\mathbf{9 5 \%} \mathbf{C l}$ & p-value \\
\hline Age $(\geq 65$ yr vs. $<65 \mathrm{yr})$ & 2.028 & $1.158-3.553$ & 0.013 \\
\hline Operation duration & 0.922 & $0.790-1.077$ & 0.306 \\
\hline Absence of TOF monitoring & 0.622 & $0.321-1.203$ & 0.158 \\
\hline Absence of reversal agent & 0.852 & $0.415-2.068$ & 0.852 \\
\hline NMBA dose & 1.061 & $0.845-1.334$ & 0.690 \\
\hline $\begin{array}{l}\text { Time from last NMBA dose to } \\
\text { TOF measurement in PACU }\end{array}$ & 0.710 & $0.562-0.899$ & 0.004 \\
\hline
\end{tabular}

$\mathrm{Cl}$ : confidence interval; NMBA: neuromuscular blocking agent; OR: odds ratio; PACU: postoperative anaesthetic care unit; TOF: train-of-four

incidence as $0 \%-19 \%$. Similarly, $52 \%$ and $64 \%$ of those surveyed in Europe and the United States, respectively, stated that PRNB occurs in $<1 \% .{ }^{(19)}$ Similarly, in the survey by Teoh et al, $63.6 \%$ stated that it occurred in $<5 \%{ }^{.24)}$ In the present survey, $94.0 \%$ and $62.7 \%$ of respondents stated that they had been taught TOF count and ratio, respectively. However, only $37.3 \%$ were confident enough to teach the use of the PNS. $8.7 \%$ stated that a lack of familiarity prevented them from using PNS monitoring. Lack of equipment $(42.7 \%)$ was also cited by our respondents as a reason for not using PNS monitoring. However, another survey showed that even with widespread (95.8\%) availability of monitors, only $13.1 \%$ would use them routinely and $60.3 \%$ would not change their practice of only sporadically monitoring their patients. ${ }^{(24)}$

The clinical signs that we studied showed poor sensitivity and specificity when used to assess for PRNB in the PACU, and are not recommended for determining recovery from neuromuscular block. ${ }^{(1,11)}$ In addition, subjective assessments of TOF fade (equating to PRNB) are not reliable. Studies have shown that most operators are unable to detect fade if TOF ratio is $\geq 0.4{ }^{(12)}$ Therefore, a TOF ratio of $0.4-0.9$ gives rise to undetectable (minimal) fade, which has been termed the 'zone of blind paralysis'. ${ }^{(25)}$ As such, only quantitative monitoring can diagnose full neuromuscular recovery.
Interestingly, there was no significant difference in the prevalence of PRNB between the group who received monitoring and the group that was not monitored. A meta-analysis showed that intraoperative quantitative neuromuscular monitoring did not reduce the prevalence of PRNB. ${ }^{(21)}$ This may be due to inappropriate use or misinterpretation of TOF monitoring, or inappropriate timing/dose of the reversal agent. With education and training as well as increased use of quantitative TOF monitoring and the use of a reversal agent, the incidence of PRNB can be significantly reduced (from $62 \%$ to $3 \%$ ). ${ }^{(18)}$ Acceleromyography has been shown to reduce postoperative hypoxaemia and improve quality of recovery in the postoperative period. ${ }^{(26)}$

The majority ( $85.7 \%$ ) of our patients received pharmacological reversal at the end of surgery, with $82.1 \%$ of them receiving neostigmine. Studies have shown that when reversal is not given, there is a high incidence of PRNB of up to $42 \%$ (TOF $<0.7$ ) to $45 \%$ (TOF < 0.9 ) of patients. ${ }^{(27)}$ Also, a large retrospective study showed that lack of reversal was an independent risk factor for anaesthesia-related postoperative morbidity and mortality. ${ }^{(9)}$ However, we did not find that the use of a reversal agent reduced the prevalence of PRNB. As mentioned, this may be due to inappropriate dose or timing of the reversal agent. Neostigmine for reversal should only be given when the TOF count is $4 .^{(25)}$ However, only $54.7 \%$ of our survey respondents agreed with this. $30.0 \%$ of the respondents followed the traditional criteria (TOF count of 2), which may lead to ineffective reversal and PRNB. In addition, when neostigmine is given to patients who have, or almost have, recovered from neuromuscular blockade, it can cause a paradoxical decrease in TOF ratio, muscle weakness and prolonged neuromuscular blockade. ${ }^{(28)}$ This explains why quantitative (compared with qualitative) TOF monitoring is considered the best method, ${ }^{(1)}$ as it helps guide the dose of reversal as well as when not to administer it.

With qualitative TOF monitoring, the dose can be titrated accordingly. $40 \mathrm{mcg} / \mathrm{kg}$ of neostigmine should be given to patients who demonstrate detectable fade. ${ }^{(1)}$ In the absence of apparent 
(visual or tactile) fade ('zone of blind paralysis'), $20 \mathrm{mcg} / \mathrm{kg}$ of neostigmine should be used instead. ${ }^{(25)}$ This lower dose of neostigmine is effective in antagonising minimal neuromuscular blockade without significant paradoxical effects. ${ }^{(29)}$ Even after administration of neostigmine, recommendations include a further wait of 10-15 minutes before waking and extubating the patient, to allow the peak effect of the drug to occur. ${ }^{(1,30)}$

Sugammadex binds specifically to steroidal NMBAs such as rocuronium and vecuronium. ${ }^{(11)}$ Unlike neostigmine, it can reliably and rapidly reverse any degree of neuromuscular block due to rocuronium. ${ }^{(31)}$ However, if sugammadex is used without neuromuscular monitoring, inappropriately administered dosages can lead to PRNB in up to $10 \%$ of patients. ${ }^{(32)}$ In our study, sugammadex was rarely used (3.5\%). Limiting factors for its use include its relatively high price, being centrally stored and the need to be prescribed on a named-patient basis.

There is a common misconception about the duration of action of NMBA that may lead to incorrect and dangerous clinical practices regarding the administration of NMBA and reversal agents. The duration of NMBA is often stated as the return of muscle twitch height (T1\%) to $25 \%$, while recovery is a return of TOF ratio $\geq 0.9$. However, only $31.3 \%$ and $24.7 \%$ of our respondents, respectively, answered these correctly. It is clinically important to note that duration of action does not equate to recovery from the action of NMBA. The duration of action of a single intubating dose $\left(2 \times \mathrm{ED}_{95}\right)$ of intermediate-acting $\mathrm{NMBAs}$ is approximately $30-40$ minutes. However, spontaneous recovery to TOF ratio $\geq 0.9$ may take up to $2-6$ hours. ${ }^{(4)}$ Without proper understanding and monitoring of this difference, patients may be at risk of PRNB. After surgery lasting one hour and two hours, only $67.3 \%$ and $35.3 \%$ of our survey respondents, respectively, stated that they would always give reversal, while $6.7 \%$ said they would not usually give reversal after two hours.

Moreover, the duration of NMBA action and the risk of PRNB is increased by a variety of factors: large interpatient variability in the speed of spontaneous recovery; slower elimination in elderly patients; hypothermia; use of halogenated volatile anaesthetic agents; and cardiac, liver and renal dysfunction. ${ }^{(4)}$ However, only $20.7 \%$ and $21.3 \%$ of our respondents stated that they would use PNS monitoring in patients with severe renal and liver disease, respectively. Infusions of NMBA also prolong its duration, but only half of our respondents used PNS monitoring in such cases.

Two independent factors were associated with PRNB in our study: age of the patient ( $\geq 65$ years) and timing of the last dose of NMBA, which is in keeping with the current literature. The odds of patients aged $\geq 65$ years having PRNB were double compared to the younger patient population. Murphy et $\mathrm{al}^{(33)}$ also found a much higher incidence of PRNB in the elderly (age 70-90 years) compared with younger (18-50 years) patients (58\% vs. 30\%, respectively). This may be explained by elderly patients having altered pharmacokinetics and pharmacodynamics of NMBAs due to reduced physiological function and muscle mass, and the presence of multiple comorbidities. These decrease the clearance and increase the duration of action of NMBAs. Advanced age has also been identified as a risk factor for poor pulmonary outcome after NMBA use: one study showed that postoperative pulmonary complications occurred in $15 \%$ of its elderly patients but in only $2 \%$ of younger patients. ${ }^{(33)}$ Elderly patients are at higher risk of these complications due to their poorer respiratory reserve: decreases in vital capacity, maximum voluntary ventilation and total lung capacity; and increases in functional residual capacity and closing volume. Elderly patients therefore require TOF monitoring and may need additional oxygen therapy, extra stimulation to maintain oxygenation and perioperative chest physiotherapy.

A shorter duration between the last dose of NMBA and TOF measurement on arrival in PACU was also associated with increased incidence of PRNB. This occurred although both NMBAs used in our study were intermediate-acting drugs. There are a few possible explanations for this. First, anaesthesiologists may not appreciate the high prevalence of PRNB or its consequences. $^{(19)} 24.0 \%$ of our survey respondents stated that the prevalence of PRNB is $<20 \%$, while $29.3 \%$ said they did not know its prevalence. Second, as discussed, the action of even intermediate NMBAs may last longer than expected.(4) Regular top-ups or a last dose of NMBA given without TOF monitoring may result in undetected deep block. TOF monitoring was used in only $17.9 \%$ of the cases in our study. Third, there may have been a lack of TOF monitoring or an error in interpretation, resulting in inappropriate timing, dose and type of reversal agent used. Our survey showed that most anaesthesiologists either routinely give neostigmine reversal or administer it depending on the time of the last dose of NMBA; only $24 \%$ of respondents used PNS to guide the usage of reversal agents.

Another risk factor identified during our univariate analysis was the large total dose of NMBA used. Our survey showed that $68.7 \%$ of respondents incorrectly reported the definition of duration of action of NMBA, with $24.7 \%$ incorrectly stating that the duration was TOF $\geq 0.9$ (i.e. recovery of block). This may lead to overdosage of NMBA and an increased risk of PRNB.

The aforementioned risk factors and the highly variable duration of action of NMBA makes it unsafe to exclude PRNB based on the time from the last dose of NMBA. Hence, proper use of PNS for neuromuscular monitoring is essential. Other factors that may potentially contribute to PRNB but were not statistically significant in our study include obesity, hypothermia and ASA 3. The lack of statistical significance may be because the majority of our patients were relatively fit and their temperatures were mostly normal $\left(36^{\circ} \mathrm{C}\right)$.

Although the overall prevalence of adverse events was relatively low $(1 \%-3 \%)$, it was significantly higher in the PRNB group. One patient (out of 335) with PRNB developed stridor requiring further dose of neostigmine in the PACU. In an institution such as ours with a high turnover of anaesthetised patients requiring NMBA, this may equate to a significant number of patients developing critical respiratory adverse events per year. A case control study by Murphy et al demonstrated that $73.8 \%$ of patients who developed critical respiratory events had a TOF $<0.7$, which suggests that PRNB may be a contributing factor to the development of such events in the PACU. ${ }^{(26)}$ Blurred vision 
and weakness can also cause considerable discomfort and may affect patient safety after transfer back to the ward. In our study, the prevalence may have been underestimated, as we did not examine adverse effects that could occur after discharge from the PACU, such as atelectasis, aspiration pneumonitis or increased length of hospital stay. We had only one case of stridor, but such airway obstruction may lead to laryngospasm and negative pressure pulmonary oedema. ${ }^{(34)}$ With proper usage of NMBA monitoring and reversal, these events are mostly preventable and patient safety can be improved.

Our study was not without limitations, and the results should be interpreted in consideration of these. It was designed as a prospective observational study. The type of anaesthesia and monitoring used intraoperatively was left to the discretion of individual consultants and large practice variability was reflected in our findings. The study was only powered to identify the prevalence of PRNB, and hence was only able to generate associations for areas of further study. We did not aim to observe if the TOF monitoring was used to determine the optimal time for tracheal intubation, interval dosing of NMBA or appropriateness for extubation (i.e. when fully recovered).

Our study may underestimate the incidence of PRNB for various reasons. First, we used acceleromyographic TOF monitoring, which has been shown to give higher values of TOF ratio than the 'gold standard' mechanomyography. ${ }^{(35)}$ It has been recommended that recovery to exclude PRNB should be redefined as acceleromyographic TOF ratio $>1.0 .{ }^{(10)}$ Second, we used uncalibrated TOF ratio using $50 \mathrm{~mA}$ currents; this may not provide the necessary supramaximal stimulation required for TOF in some patients. Third, our study was confined to the PACU and we did not investigate the long-term effects of PRNB. Fourth, the site of TOF monitoring affects its interpretation. The muscle most commonly used to monitor TOF, the adductor pollicis, is less sensitive to NMBAs compared to the muscles of the tongue, floor of the mouth and the pharyngeal airway. Therefore, PRNB of the upper airway muscles could be present despite recovery of TOF ratio at the adductor pollicis. In our survey, $67.3 \%$ of the respondents gave incorrect answers regarding the order of resistance of various muscles to NMBAs. Although investigators were not blinded to the patient's management regarding the use of NMBAs or reversal agents, we used an objective endpoint (i.e. TOF ratio).

As our overall risk of respiratory complications was low, we were unable to establish a firm association or causality between PRNB and the complications. The study was also conducted within a PACU setting with a second review at 24 hours. Therefore, we were unable to identify any long-term complications such as aspiration, pneumonia, prolonged hospital stays or other associated morbidity.

In conclusion, PRNB remains a clinically significant problem and rates of routine PNS monitoring are low in our institution. This is compounded by incorrect knowledge and inappropriate clinical practices related to neuromuscular blockade. Further education is needed to enhance the knowledge of anaesthesiologists. We also strongly encourage adherence to guidelines in the use of
NMBAs and reversal agents as well as PNS monitoring. This is especially important in the elderly when high doses of NMBAs are used, after a shorter duration of surgery and when the last dose of NMBA is given close to the end of the surgery.

\section{SUPPLEMENTARY MATERIAL}

The appendices are available online at https://doi.org/10.11622/ smedj.2019118.

\section{REFERENCES}

1. Checketts MR, Alladi R, Ferguson K, et al; Association of Anaesthetists of Great Britain and Ireland. Recommendations for standards of monitoring during anaesthesia and recovery 2015 : Association of Anaesthetists of Great Britain and Ireland. Anaesthesia 2016; 71:85-93.

2. Maybauer DM, Geldner G, Blobner M, et al. Incidence and duration of residual paralysis at the end of surgery after multiple administrations of cisatracurium and rocuronium. Anaesthesia 2007; 62:12-7.

3. Kim KS, Lew SH, Cho HY, Cheong MA. Residual paralysis induced by either vecuronium or rocuronium after reversal with pyridostigmine. Anesth Analg 2002; 95:1656-60.

4. Debaene B, Plaud B, Dilly MP, Donati F. Residual paralysis in the PACU after a single intubating dose of nondepolarizing muscle relaxant with an intermediate duration of action. Anesthesiology 2003; 98:1042-8.

5. Sundman E, Witt H, Olsson R, et al. The incidence and mechanisms of pharyngeal and upper esophageal dysfunction in partially paralyzed humans: pharyngeal videoradiography and simultaneous manometry after atracurium. Anesthesiology 2000; 92:977-84.

6. Eikermann M, Vogt FM, Herbstreit F, et al. The predisposition to inspiratory upper airway collapse during partial neuromuscular blockade. Am J Respir Crit Care Med 2007; 175:9-15.

7. Eikermann M, Groeben H, Hüsing J, Peters J. Accelerometry of adductor pollicis muscle predicts recovery of respiratory function from neuromuscular blockade. Anesthesiology 2003; 98:1333-7.

8. Bulka CM, Terekhov MA, Martin BJ, et al. Nondepolarizing neuromuscular blocking agents, reversal, and risk of postoperative pneumonia. Anesthesiology 2016; 125:647-55.

9. Arbous MS, Meursing AE, van Kleef JW, et al. Impact of anesthesia management characteristics on severe morbidity and mortality. Anesthesiology 2005; 102:257-68; quiz 491-2.

10. Capron F, Alla F, Hottier C, Meistelman C, Fuchs-Buder T. Can acceleromyography detect low levels of residual paralysis? A probability approach to detect a mechanomyographic train-of-four ratio of 0.9. Anesthesiology 2004; 100:1119-24.

11. Hunter JM. Reversal of residual neuromuscular block: complications associated with perioperative management of muscle relaxation. Br J Anaesth 2017; 119(Suppl 1):i53-62.

12. Viby-Mogensen J, Jensen $\mathrm{NH}$, Engbaek J, et al. Tactile and visual evaluation of the response to train-of-four nerve stimulation. Anesthesiology 1985; 63:440-3.

13. Drenck NE, Ueda N, Olsen NV, et al. Manual evaluation of residual curarization using double burst stimulation: a comparison with train-of-four. Anesthesiology 1989; 70:578-81

14. Capron F, Fortier LP, Racine S, Donati F. Tactile fade detection with hand or wrist stimulation using train-of-four, double-burst stimulation, 50-hertz tetanus, 100-hertz tetanus, and acceleromyography. Anesth Analg 2006; 102:1578-84.

15. Fuchs-Buder T, Claudius C, Skovgaard LT, et al; 8th International Neuromuscular Meeting. Good clinical research practice in pharmacodynamic studies of neuromuscular blocking agents II: the Stockholm revision. Acta Anaesthesiol Scand 2007; 51:789-808

16. Murphy GS, Brull SJ. Residual neuromuscular block: lessons unlearned. Part I: definitions, incidence, and adverse physiologic effects of residual neuromuscular block. Anesth Analg 2010; 111:120-8.

17. Apfelbaum JL, Silverstein JH, Chung FF, et al; American Society of Anesthesiologists Task Force on Postanesthetic Care. Practice guidelines for postanesthetic care: an updated report by the American Society of Anesthesiologists Task Force on Postanesthetic Care. Anesthesiology 2013; 118:291-307.

18. Baillard C, Clec'h C, Catineau J, et al. Postoperative residual neuromuscular block: a survey of management. Br J Anaesth 2005; 95:622-6.

19. Naguib M, Kopman AF, Lien CA, et al. A survey of current management of neuromuscular block in the United States and Europe. Anesth Analg 2010; 111:110-9.

20. Pourhoseingholi MA, Vahedi M, Rahimzadeh M. Sample size calculation in medical studies. Gastroenterol Hepatol Bed Bench 2013; 6:14-7.

21. Naguib M, Kopman AF, Ensor JE. Neuromuscular monitoring and postoperative residual curarisation: a meta-analysis. Br J Anaesth 2007; 98:302-16.

22. Foldes FF, Nagashima H, Nguyen HD, et al. The neuromuscular effects of ORG9426 
in patients receiving balanced anesthesia. Anesthesiology 1991; 75:191-6.

23. Basta SJ, Ali HH, Savarese JJ, et al. Clinical pharmacology of atracurium besylate (BW 33A): a new non-depolarizing muscle relaxant. Anesth Analg 1982; 61:723-9.

24. Teoh WH, Ledowski T, Tseng PS. Current trends in neuromuscular blockade, management, and monitoring amongst Singaporean anaesthetists. Anesthesiol Res Pract 2016; 2016:7284146.

25. Thilen SR, Bhananker SM. Qualitative neuromuscular monitoring: how to optimize the use of a peripheral nerve stimulator to reduce the risk of residual neuromuscular blockade. Curr Anesthesiol Rep 2016; 6:164-9.

26. Murphy GS, Szokol JW, Marymont JH, et al. Residual neuromuscular blockade and critical respiratory events in the postanesthesia care unit. Anesth Analg 2008; 107:130-7.

27. Baillard C, Gehan G, Reboul-Marty J, et al. Residual curarization in the recovery room after vecuronium. Br J Anaesth 2000; 84:394-5.

28. Caldwell JE. Reversal of residual neuromuscular block with neostigmine at one to four hours after a single intubating dose of vecuronium. Anesth Analg 1995; 80:1168-74.

29. Johnson RA, Harper NJ. Antagonism of moderate degrees of vecuronium-induced neuromuscular block by small doses of neostigmine. Br J Anaesth 1989; 62:483-7.

30. Haerter F, Eikermann M. Reversing neuromuscular blockade: inhibitors of the acetylcholinesterase versus the encapsulating agents sugammadex and calabadion. Expert Opin Pharmacother 2016; 17:819-33.

31. Groudine SB, Soto R, Lien C, Drover D, Roberts K. A randomized, dose-finding, phase II study of the selective relaxant binding drug, Sugammadex, capable of safely reversing profound rocuronium-induced neuromuscular block. Anesth Analg 2007; 104:555-62.

32. Kotake Y, Ochiai R, Suzuki T, et al. Reversal with sugammadex in the absence of monitoring did not preclude residual neuromuscular block. Anesth Analg 2013; 117:345-51.

33. Murphy GS, Szokol JW, Avram MJ, et al. Residual neuromuscular block in the elderly: incidence and clinical implications. Anesthesiology 2015; 123:1322-36.

34. Lemyze M, Mallat J. Understanding negative pressure pulmonary edema. Intensive Care Med 2014; 40:1140-3.

35. Claudius C, Skovgaard LT, Viby-Mogensen J. Is the performance of acceleromyography improved with preload and normalization? Anesthesiology 2009; 110:1261-70 


\section{Appendix 1}

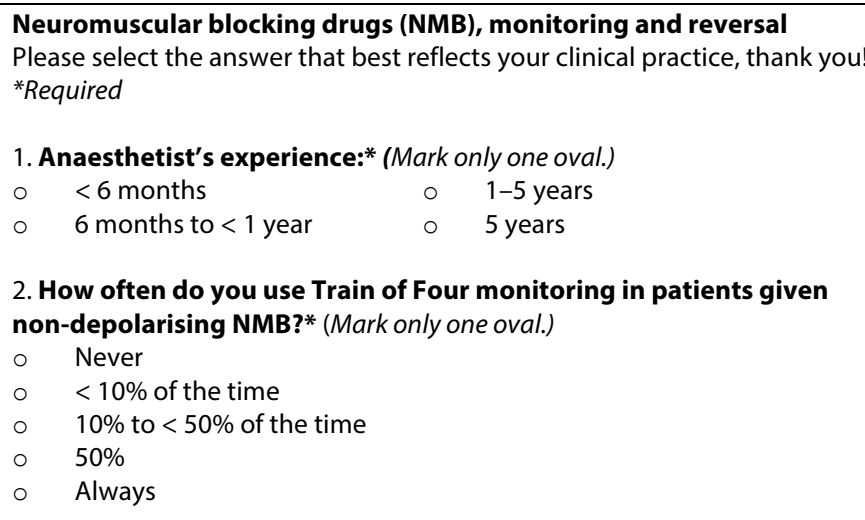

3. Use of a peripheral nerve stimulator is essential for all stages of anaesthesia when NMB drugs are administered.* (Mark only one oval.)

- Strongly disagree

- Disagree

Neither agree nor disagree

Agree

- Strongly agree

4. Have been taught how to use Train of Four COUNT in theatres?* (Mark only one oval.)

- Yes $\quad$ No

5. Have been taught how to use Train of Four RATIO in theatres?* (Mark only one oval.)

$\circ$ Yes $\circ$ No

6. Case: you give a standard intubating dose of NMB (atracurium $0.5 \mathrm{mg} / \mathrm{kg}$ or rocuronium $0.6 \mathrm{mg} / \mathrm{kg}$ ) for intubation, which lasts 30-40 mins, after surgery lasting ONE hour, do you give reversal?* (Mark only one oval.)

- Yes, always

- Yes, depending on time of last dose of NMB

- Yes, depending on if the patient has started breathing

- Yes, depending on mixture of time of last dose of NMB and if the patient has started breathing

- Yes, depending on Train of Four COUNT

Yes, depending on Train of Four RATIO

No, not usually

No, never

7. Case: you give a standard intubating dose of NMB (atracurium $0.5 \mathrm{mg} / \mathrm{kg}$ or rocuronium $0.6 \mathrm{mg} / \mathrm{kg}$ ) for intubation, which lasts 30-40 mins, after surgery lasting TWO hours, do you give reversal?* (You can tick one or more boxes but please be consistent with yes and no.)

- Yes, always

- Yes, depending on time of last dose of NMB

- Yes, depending on if the patient has started breathing

- Yes, depending on mixture of time of last dose of NMB and if the patient has started breathing

- Yes, depending on Train of Four COUNT

Yes, depending on Train of Four RATIO

No, not usually

No, never

\section{A patient is fully reversed when you have:}

(Mark only one oval.)

- Train of Four ratio $\geq 0.7$

Post tetanic count $\geq 10$

Train of Four ratio $\geq 0.9$

Double burst stimulation with strong twitches and no fade

Train of Four with four strong twitches and no fade Don't know

8. You GENERALLY use train of four monitoring for the following cases if given non-depolarising NMB:* (You can tick one or more boxes.)

- Short cases

Long cases

Difficult airway cases

Obese or morbidly obese

Laparoscopic cases

Renal disease (severe)

Liver disease (severe)

Patients on IV infusion of NMB drugs

I don't generally/never use Train of Four monitoring

\section{For CARDIAC senior anaesthetists (AC, C or SC)} anaesthetising CARDIAC CASES, you generally use Train of Four monitoring for your cases:* (Mark only one oval.)

- Yes 0 No

- I'm not a cardiac senior anaesthetist

10. For NEURO senior anaesthetists (AC, C or SC) anaesthetising NEURO cases, or juniors in charge of a neuro EOT case, you generally use Train of Four monitoring for your cases:* (Mark only one oval.)

- Yes

- No

- I'm not a neuro senior anaesthetist or junior in charge of a neuro EOT case

\section{I would use Train of Four monitoring MORE often}

BUT:* (You can tick one or more boxes.)

- I not familiar with it

- My senior in theatre with me has said that they do not want to use it

- There are not enough Train of Four monitors in theatres I don't think it's necessary

Wouldn't use it more, as I use it often or all the time

12. Which of the following do you use for Train of Four monitoring?* (You can tick one or more boxes.)

Facial nerve orbicularis oculi muscle

Facial nerve corrugator supercilii muscle

Ulnar nerve adductor pollicis muscle

Common peroneal nerve big toe

Posterior tibial nerve big toe

I don't use Train of Four monitoring

13. Definition of duration of a standard intubating dose of NMB is from time to IV administration of the NMB to:* (Mark only one oval.)

T1 twitch return of $25 \%$ baseline

TOF ratio of 0.9

TOF count 4 twitches with no fade

$\mathrm{EtCO}_{2}$ showing diaphragmatic notching, or return of adequate spontaneous ventilation

- Don't know
21. If using neostigmine as a reversal agent, the ideal time to give reversal is:* (Mark only one oval.)

- 30-60 minutes after the last dose of NMB depending on NMB used

TOF count 2 twitches

TOF count 4 twitches

Post-tetanic count of 10

Don't know 


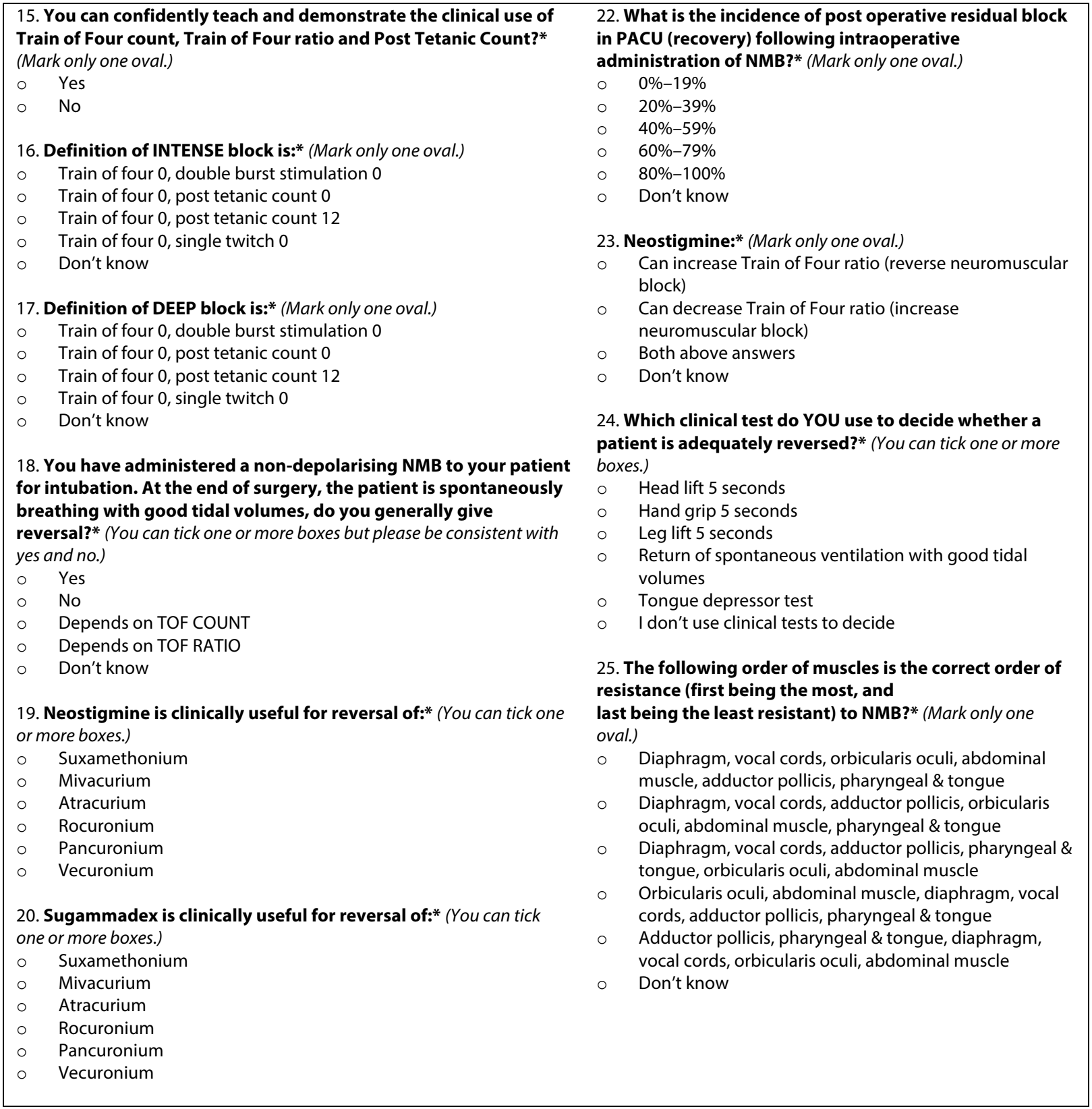




\section{Appendix 2}

Results of postoperative residual neuromuscular block survey $(n=150)$.

\begin{tabular}{|l|l|}
\hline Question \\
\hline 1. Anaesthetist's experience \\
\hline$<6$ months & 2 \\
\hline 6 months to $<1$ year & 7 \\
\hline $1-5$ years & 5 \\
\hline$>5$ years & 6 \\
\hline
\end{tabular}

\section{No. (\%)

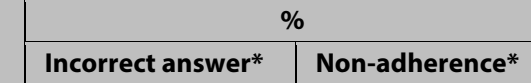

$23(15.3)$

$7(4.7)$

$58(38.7)$

$62(41.3)$

2. How often do you use TOF monitoring in patients given non-depolarising NMB?

\begin{tabular}{|l|l|}
\hline Never & $12(8.0)$ \\
\hline$<10 \%$ of the time & $116(77.3)$ \\
\hline $10 \%$ to $<50 \%$ of the time & $16(10.7)$ \\
\hline$>50 \%$ of the time & $4(2.7)$ \\
\hline $100 \%^{\dagger}$ & $2(1.3)$ \\
\hline
\end{tabular}

3. Use of a peripheral nerve stimulator is essential for all stages of anaesthesia when NMB drugs are administered.

\begin{tabular}{|c|c|c|}
\hline Strongly disagree & $5(3.3)$ & \multirow{5}{*}{62.0} \\
\hline Disagree & $42(28.0)$ & \\
\hline Neither agree nor disagree & $46(30.7)$ & \\
\hline Agree $^{\dagger}$ & $48(32.0)$ & \\
\hline Strongly agree $^{\dagger}$ & $9(6.0)$ & \\
\hline \multicolumn{3}{|c|}{ 4. Have you been taught TOF count in theatres? } \\
\hline Yes & $141(94.0)$ & \\
\hline No & $9(6.0)$ & \\
\hline \multicolumn{3}{|c|}{ 5. Have you been taught TOF ratio in theatres? } \\
\hline Yes & $94(62.7)$ & \\
\hline No & $56(37.3)$ & \\
\hline
\end{tabular}

6. You give a standard intubating dose of NMB (atracurium $0.5 \mathrm{mg} / \mathrm{kg}$ or rocuronium $0.6 \mathrm{mg} / \mathrm{kg}$ ) for intubation, which lasts $30-40$ $\min$. After surgery lasting ONE hour, do you give reversal?

\begin{tabular}{|c|c|c|}
\hline Yes, always ${ }^{\ddagger}$ & $101(67.3)$ & \\
\hline Yes, depending on time of last dose of NMB & $18(12.0)$ & 12.0 \\
\hline Yes, depending on if the patient has started breathing & $1(0.7)$ & 0.7 \\
\hline $\begin{array}{l}\text { Yes, depending on mixture of time of last dose of NMB and if the } \\
\text { patient has started breathing }\end{array}$ & $16(10.7)$ & 10.7 \\
\hline Yes, depending on TOF count $^{\dagger}$ & $8(5.3)$ & 94.7 \\
\hline Yes, depending on TOF ratio ${ }^{\dagger}$ & $5(3.3)$ & 96.7 \\
\hline No, not usually & $0(0)$ & 0 \\
\hline No, never & $1(0.7)$ & 0.7 \\
\hline
\end{tabular}

7. You give a standard intubating dose of NMB (atracurium $0.5 \mathrm{mg} / \mathrm{kg}$ or rocuronium $0.6 \mathrm{mg} / \mathrm{kg}$ ) for intubation, which lasts $30-40$ mins. After surgery lasting TWO hours, do you give reversal? ${ }^{\S}$

\begin{tabular}{|c|c|c|}
\hline Yes, always ${ }^{\ddagger}$ & $53(35.3)$ & \\
\hline Yes, depending on time of last dose of NMB & $44(29.3)$ & 29.3 \\
\hline Yes, depending on if the patient has started breathing & $10(6.7)$ & 6.7 \\
\hline $\begin{array}{l}\text { Yes, depending on mixture of time of last dose of NMB and if the } \\
\text { patient has started breathing }\end{array}$ & $38(25.3)$ & 25.3 \\
\hline Yes, depending on TOF count ${ }^{\dagger}$ & $20(13.3)$ & 86.7 \\
\hline Yes, depending on TOF ratio ${ }^{\dagger}$ & $16(10.7)$ & 89.3 \\
\hline No, not usually & $10(6.7)$ & 6.7 \\
\hline No, never & $0(0)$ & 0 \\
\hline \multicolumn{3}{|c|}{ 8. You generally use TOF monitoring for the following cases if given non-depolarising NMBA $^{\S}$} \\
\hline Short cases $^{\dagger}$ & $53(35.3)$ & 64.7 \\
\hline Long case $^{\dagger}$ & $32(21.3)$ & 78.7 \\
\hline Difficult airway cases $^{\dagger}$ & $65(43.3)$ & 56.7 \\
\hline Obese or morbidly obese ${ }^{\dagger}$ & $62(41.3)$ & 58.7 \\
\hline Laparoscopic cases $^{\dagger}$ & $8(5.3)$ & 94.7 \\
\hline Renal disease (severe) $^{\dagger}$ & $31(20.7)$ & 79.3 \\
\hline
\end{tabular}




\begin{tabular}{|c|c|c|c|}
\hline Liver disease (severe) $^{\dagger}$ & $32(21.3)$ & & 78.7 \\
\hline Patients on intravenous infusion of NMB drugs ${ }^{\dagger}$ & $74(49.3)$ & & 50.7 \\
\hline I don't generally/never use TOF monitoring & $38(25.3)$ & & 25.3 \\
\hline \multicolumn{4}{|c|}{ 9. For cardiac anaesthetists anaesthetisting cardiac cases, you generally use TOF monitoring for your cases: } \\
\hline Yes & $0(0)$ & & \\
\hline No & $10(6.7)$ & & \\
\hline I'm not a cardiac senior anaesthetist & $140(93.3)$ & & \\
\hline \multicolumn{4}{|c|}{$\begin{array}{l}\text { 10. For neurology senior anaesthetists anaesthetizing neurosurgical cases, or juniors in charge of a neurosurgical emergency case, } \\
\text { you generally use TOF monitoring for your cases: }\end{array}$} \\
\hline Yes & $4(2.7)$ & & \\
\hline No & $34(22.7)$ & & \\
\hline I'm not a neuroanaesthetist or junior in charge of neurosurgical cases & $112(74.7)$ & & \\
\hline \multicolumn{4}{|l|}{ 11. I would use TOF monitoring more often but: ${ }^{\S}$} \\
\hline I'm not familiar with it & $13(8.7)$ & & \\
\hline My senior in theatre with me has said that they do not want to use it & $56(37.3)$ & & \\
\hline There are not enough TOF monitors in theatres & $64(42.7)$ & & \\
\hline I don't think it's necessary & $51(34.0)$ & & \\
\hline Wouldn't use it more, as I use it often or all the time & $7(4.7)$ & & \\
\hline \multicolumn{4}{|l|}{ 12. Which of the following do you use TOF monitoring? ${ }^{\S}$} \\
\hline Facial nerve - orbicularis oculi muscle & $35(23.3)$ & & \\
\hline Facial nerve - corrugator supercilii muscle & $5(3.3)$ & & \\
\hline Ulnar nerve - adductor pollicis muscle & $142(94.7)$ & & \\
\hline Common peroneal nerve - big toe & $9(6.0)$ & & \\
\hline Posterior tibial nerve - big toe & $9(6.0)$ & & \\
\hline I don't use TOF monitoring & $7(4.7)$ & & \\
\hline \multicolumn{4}{|c|}{ 13. Definition of duration of a standard intubating dose of NMB is from time to IV administration of the NMB to: } \\
\hline T1 twitch return of $25 \%$ baseline $^{\dagger}$ & $47(31.3)$ & \multirow{5}{*}{68.7} & \\
\hline TOF ratio of 0.9 & $37(24.7)$ & & \\
\hline TOF count 4 twitches with no fade & $27(18.0)$ & & \\
\hline $\begin{array}{l}\mathrm{EtCO}_{2} \text { showing diaphragmatic notching or return of adequate } \\
\text { spontaneous ventilation }\end{array}$ & $4(2.7)$ & & \\
\hline Don't know & $35(23.3)$ & & \\
\hline \multicolumn{4}{|l|}{ 14. A patient is fully reversed when you have: } \\
\hline TOF ratio $\geq 0.7$ & $7(4.7)$ & \multirow{6}{*}{46.0} & \\
\hline Post tetanic count $\geq 10$ & $1(0.7)$ & & \\
\hline TOF ratio $\geq 0.9^{\dagger}$ & $81(54.0)$ & & \\
\hline Double burst stimulation with strong twitches and no fade & $8(5.3)$ & & \\
\hline TOF with four strong twitches and no fade & $41(27.3)$ & & \\
\hline Don't know & $5(3.3)$ & & \\
\hline \multicolumn{4}{|c|}{ 15. You can confidently teach and demonstrate the clinical use of train of four count, train of four ratio and post-tetanic count? } \\
\hline Yes & $56(37.3)$ & & \\
\hline No & $94(62.7)$ & & \\
\hline \multicolumn{4}{|l|}{ 16. Definition of INTENSE block is: } \\
\hline TOF 0 , double burst stimulation 0 & $16(10.7)$ & \multirow{5}{*}{39.3} & \\
\hline TOF 0 , post-tetanic count $0^{\dagger}$ & $91(60.7)$ & & \\
\hline TOF 0 , post-tetanic count $1-2$ & $13(8.7)$ & & \\
\hline TOF 0 , single twitch 0 & $4(2.7)$ & & \\
\hline Don't know & $26(17.3)$ & & \\
\hline \multicolumn{4}{|l|}{ 17. Definition of DEEP block is: } \\
\hline TOF 0 , double burst stimulation 0 & $10(6.7)$ & \multirow{5}{*}{43.3} & \\
\hline TOF 0 , post-tetanic count 0 & $22(14.7)$ & & \\
\hline TOF 0 , post-tetanic count $1-2^{\dagger}$ & $85(56.7)$ & & \\
\hline TOF 0 , single twitch 0 & $2(1.3)$ & & \\
\hline Don't know & $31(20.7)$ & & \\
\hline \multicolumn{4}{|c|}{$\begin{array}{l}\text { 18. You have administered a non-depolarising NMB to your patient for intubation. At the end of surgery, the patient is } \\
\text { spontaneously breathing with good tidal volumes, do you generally give reversal? }\end{array}$} \\
\hline Yes $^{\ddagger}$ & $91(60.7)$ & & \\
\hline
\end{tabular}




\begin{tabular}{|c|c|c|c|}
\hline No & $29(19.3)$ & & 19.3 \\
\hline Depends on TOF count ${ }^{\dagger}$ & $26(17.3)$ & & 82.7 \\
\hline Depends on TOF ratio $^{\dagger}$ & $35(23.3)$ & & 76.7 \\
\hline Don't know & $2(1.3)$ & & 1.3 \\
\hline \multicolumn{4}{|l|}{ 19. Neostigmine is clinically useful for the reversal of: ${ }^{\$}$} \\
\hline Suxamethonium & $4(2.7)$ & 2.7 & \\
\hline Mivacurium & $45(30.0)$ & 30.0 & \\
\hline Atracurium $^{\dagger}$ & $150(100.0)$ & 0 & \\
\hline Rocuronium $^{\dagger}$ & $126(84.0)$ & 16.0 & \\
\hline Pancuronium $^{\dagger}$ & $111(74.0)$ & 26.0 & \\
\hline Vecuronium $^{\dagger}$ & $118(78.7)$ & 21.3 & \\
\hline \multicolumn{4}{|l|}{ 20. Sugammadex is clinically useful for the reversal of: ${ }^{5}$} \\
\hline Suxamethonium & $5(3.3)$ & 3.3 & \\
\hline Mivacurium & $3(2.0)$ & 2.0 & \\
\hline Atracurium & $1(0.7)$ & 0.7 & \\
\hline Rocuronium $^{\dagger}$ & $147(98.0)$ & 2.0 & \\
\hline Pancuronium ${ }^{\ddagger}$ & $28(18.7)$ & & \\
\hline Vecuronium $^{\dagger}$ & $72(48.0)$ & 52.0 & \\
\hline \multicolumn{4}{|l|}{ 21. If using neostigmine, the ideal time to give it is: } \\
\hline $30-60$ min after the last dose of NMB, depending on NMB used & $15(10.0)$ & \multirow{5}{*}{45.3} & \\
\hline TOF count 2 twitches & $45(30.0)$ & & \\
\hline TOF count 4 twitches $^{\dagger}$ & $82(54.7)$ & & \\
\hline Post-tetanic count of 10 & $3(2.0)$ & & \\
\hline Don't know & $5(3.3)$ & & \\
\hline \multicolumn{4}{|c|}{ 22. What is the incidence of postoperative residual block in PACU after intraoperative administration of NMB? } \\
\hline $0 \%-19 \%$ & $36(24.0)$ & \multirow{6}{*}{58.7} & \\
\hline $20 \%-39 \%{ }^{\dagger}$ & $42(28.0)$ & & \\
\hline $40 \%-59 \%^{\dagger}$ & $20(13.3)$ & & \\
\hline $60 \%-79 \%$ & $6(4.0)$ & & \\
\hline $80 \%-100 \%$ & $2(1.3)$ & & \\
\hline Don't know & $44(29.3)$ & & \\
\hline \multicolumn{4}{|l|}{ 23. Neostigmine } \\
\hline Can increase TOF ratio (reverse NMB) & $49(32.7)$ & \multirow{4}{*}{43.3} & \\
\hline Can decrease TOF ratio (increase NMB) & $1(0.7)$ & & \\
\hline Both above answers $^{\dagger}$ & $85(56.7)$ & & \\
\hline Don't know & $15(10.0)$ & & \\
\hline \multicolumn{4}{|c|}{ 24. What clinical tests do you use to decide whether a patient is adequately reversed? ${ }^{\S}$} \\
\hline Head lift 5 seconds & $109(72.7)$ & & 72.7 \\
\hline Hand grip 5 seconds & $60(40.0)$ & & 40.0 \\
\hline Leg lift 5 seconds & $8(5.3)$ & & 5.3 \\
\hline Return of spontaneous ventilation with good tidal volumes & $99(66.0)$ & & 66.0 \\
\hline Tongue depressor test & $4(2.7)$ & & 2.7 \\
\hline I don't use clinical tests to decide ${ }^{\dagger}$ & $15(10.0)$ & & 90.0 \\
\hline \multicolumn{4}{|c|}{$\begin{array}{l}\text { 25. The following order of muscles is the correct order of resistance (first being the most, and last being the least resistant) to } \\
\text { NMB? }\end{array}$} \\
\hline $\begin{array}{l}\text { Diaphragm, vocal cords, orbicularis oculi, abdominal muscle, adductor } \\
\text { pollicis, pharyngeal \& tongue }\end{array}$ & $49(32.7)$ & \multirow{6}{*}{67.3} & \\
\hline $\begin{array}{l}\text { Diaphragm, vocal cords, adductor pollicis, orbicularis oculi, abdominal } \\
\text { muscle, pharyngeal \& tongue }\end{array}$ & $24(16.0)$ & & \\
\hline $\begin{array}{l}\text { Diaphragm, vocal cords, adductor pollicis, pharyngeal \& tongue, } \\
\text { orbicularis oculi, abdominal muscle }\end{array}$ & $26(17.3)$ & & \\
\hline $\begin{array}{l}\text { Orbicularis oculi, abdominal muscle, diaphragm, vocal cords, adductor } \\
\text { pollicis, pharyngeal \& tongue }\end{array}$ & $15(10.0)$ & & \\
\hline $\begin{array}{l}\text { Adductor pollicis, pharyngeal \& tongue, diaphragm, vocal cords, } \\
\text { orbicularis oculi, abdominal muscle }\end{array}$ & $12(8.0)$ & & \\
\hline Don't know & $24(16.0)$ & & \\
\hline
\end{tabular}


only one answer allowed, \% incorrect answer or non-adherence was calculated per question $=((150-$ correct responses $) / 150) \times 100$. For multiple choice questions with multiple answers allowed, \% incorrect answer or non-adherence was calculated per answer option. If the answer was incorrect, the \% incorrect or non-adherence was the same $\%$ as those who answered this option. If the answer was correct, \% incorrect or non-adherence $=((150-$ correct responses) $/ 150) \times 100$. +Correct answer. \#Equivocal answers were possible, so \% incorrect answer or non-adherence were not calculated. $\S M u l t i p l e$ answers allowed. IV: intravenous; NMB: neuromuscular block; PACU: postoperative anaesthetic care unit; TOF: train of four 